\title{
Baicalein induces apoptosis in esophageal squamous cell carcinoma cells through modulation of the PI3K/Akt pathway
}

\author{
HONG-BO ZHANG ${ }^{1}$, PING LU ${ }^{2}$, QING-YIN GUO ${ }^{3}$, ZHEN-HUA ZHANG ${ }^{1}$ and XIANG-YU MENG ${ }^{1}$ \\ ${ }^{1}$ Department of Anatomy and Cell Biology, School of Basic Medicine, Zhengzhou University, Zhengzhou 450001; \\ ${ }^{2}$ School of Pharmacy and ${ }^{3}$ First Clinical College, Henan University of Traditional Chinese Medicine, \\ Zhengzhou 450008, P.R. China
}

Received August 24, 2012; Accepted November 29, 2012

DOI: $10.3892 / 01.2012 .1069$

\begin{abstract}
Baicalein, a flavone present in Scutellaria baicalensis Georgi, has been demonstrated to possess antitumor activity in a variety of cancer cells in vitro. However, its effects on the growth inhibition and induction of apoptosis in human esophageal carcinoma cells remain unclear. The aims of this study were to determine whether cultured EC-109 esophageal squamous cell carcinoma (ESCC) cells undergo apoptosis when treated with baicalein and to investigate the underlying mechanisms in vitro. Cell growth was measured using MTT and plate colony formation assays. Induction of apoptosis was examined using Hoechst 33258 staining, flow cytometry analysis and a DNA fragmentation assay. The mechanisms underlying the observed growth suppression were examined using western blot analysis. The results demonstrated that treatment of EC-109 cells with baicalein for $48 \mathrm{~h}$ markedly decreased the rate of cell viability. Colony formation was almost fully suppressed at $40 \mu \mathrm{M}$ baicalein. EC-109 cells underwent apoptosis in response to baicalein treatment, demonstrated by an increase in the percentage of cells stainable with Hoechst 33258 and Annexin V-FITC/PI, increased DNA fragmentation and activation of the intrinsic (mitochondrial) pathway for cell death. The latter was characterized by increased expression of the cleaved forms of caspase- 9 and -3 , and poly (ADP-ribose) polymerase (PARP). Additionally, baicalein was found to downregulate anti-apoptotic components and upregulate apoptotic components of the PI3K/Akt pathway. In conclusion, baicalein induces apoptosis in EC-109 cells through modulation of the PI3K/Akt pathway, thus providing further understanding of the molecular mechanisms
\end{abstract}

Correspondence to: Dr Hong-Bo Zhang, Department of Anatomy and Cell Biology, School of Basic Medicine, Zhengzhou University, 100 Kexue Road, Zhengzhou 450001, China

E-mail: zhanghongbo1975@gmail.com

Key words: cell apoptosis, baicalein, esophageal squamous cell carcinoma, PI3K/Akt signaling pathway of baicalein action in esophageal carcinoma. Therefore, the present study revealed that baicalein significantly inhibits growth and induces apoptosis in EC-109 human ESCC cells in vitro.

\section{Introduction}

Esophageal cancer is one of the most aggressive human cancers. It is currently the sixth leading cause of cancerrelated mortality worldwide $(1,2)$. Cancer of the esophagus is associated with a very poor survival rate. Even in the most developed countries, the 5-year survival rate ranges merely from $10-16 \%$ (3). In China, the mortality rate of esophageal cancer is ranked fourth among all cancer-related mortalities, and esophageal squamous cell carcinoma (ESCC) is the major histological type (4,5). Despite significant advances in screening, surgical care and chemoradiotherapy techniques, the prognosis for patients with ESCC remains poor $(6,7)$. Thus, it is necessary to search for new treatment strategies.

Numerous Chinese herbs have been discovered to be potential sources of antitumor drugs $(8,9)$. Baicalein (5,6,7-trihydroxyflavone) is one of the key flavones present in Scutellaria baicalensis Georgi, which has been used for the treatment of inflammation, cardiovascular disease and microbial infections (10-12). Accumulating evidence has demonstrated the antitumor activity of this flavone in a variety of human cancer cell lines (13-16). The molecular mechanisms underlying these effects are speculated to include the modulation of several classes of cyclin-dependent kinases (CDKs) and $\mathrm{CDK}$ regulatory subunits (cyclins) to inhibit cell cylce progression $(16,17)$, suppression of proliferation and induction of apoptosis (via activation of the mitochondrial pathway and DNA fragmentation) in malignant cells $(14,16,18-20)$.

The PI3K/Akt pathway plays a critical role in mammalian cell survival and resistance to apoptosis. Alterations in the PI3K/Akt signaling pathway have also been implicated in the occurrence and development of human cancer $(21,22)$. Activation of the PI3K/Akt pathway has been demonstrated to promote survival of esophageal cancer cells in vitro, as well as tumorigenicity and metastasis of human esophageal cancer in vivo (23-25). In addition, it has been demonstrated that the 
expression of cell proliferation and cell cycle-related proteins (such as cyclin D1 and p27), as well as cell apoptosis-related proteins (including Bcl-2 and Bax), as the downstream targets of the PI3K/Akt pathway, were regulated by the PI3K/Akt pathway in human ESCC cells (26).

Notably, baicalein-induced apoptosis and proliferation retardation has been demonstrated to be mediated by downregulation of the PI3K/Akt pathway in human epidermoid carcinoma (27) and bladder cancer (17) cells. However, no studies thus far have examined the effects of proliferation inhibition and induced apoptosis of baicalein on esophageal carcinoma cells. Therefore, we conducted an investigation to ascertain whether baicalein was capable of downregulating the PI3K/Akt pathway in ESCC EC-109 cells concurrently with induction of apoptotic cell death. To our knowledge, the present study provides the first direct evidence that baicalein induces apoptosis in ESCC cells, and that the underlying mechanism may be activation of the PI3K/Akt signaling pathway.

\section{Materials and methods}

Chemicals and reagents. RPMI-1640 medium, fetal bovine serum (FBS), penicillin G and streptomycin were obtained from Invitrogen Life Technologies (Carlsbad, CA, USA). Dimethyl sulfoxide (DMSO), ribonuclease A (RNase A), Annexin V-Fluorescein Isothiocyanate (FITC) Apoptosis Detection kit, 3-(4,5-dimethylthiazol-2-yl)-2,5-diphenyltetrazolium bromide (MTT) and baicalein $\left(\mathrm{C}_{15} \mathrm{H}_{10} \mathrm{O}_{5}\right.$, MW 270.24) were purchased from Sigma-Aldrich (St. Louis, MO, USA). All antibodies (mouse antibodies specific for $\beta$-actin, procaspase-9 and -3, cleaved caspase-9 and -3, PARP, Bcl-2, Bax, Akt, p-Akt, NF- $\kappa$ B, I $\mathrm{B}, \mathrm{p}-\mathrm{I} \kappa \mathrm{B}, \mathrm{mTOR}$ and p-mTOR) and horseradish peroxidase-conjugated goat anti-mouse secondary antibodies were purchased from Santa Cruz Biotechnology, Inc. (Santa Cruz, CA, USA). Baicalein was dissolved in DMSO. The final DMSO concentration was $<1 \%$ o (v/v) in all experiments.

Cell culture. Human ESCC EC-109 cell line was obtained from the China Center for Type Culture Collection (CCTCC; Wuhan, China). Cultures were maintained in RPMI-1640 medium supplemented with $10 \%$ FBS and antibiotics (100 U/ml penicillin and $100 \mu \mathrm{g} / \mathrm{ml}$ streptomycin) at $37^{\circ} \mathrm{C}$ in a humidified atmosphere containing $5 \% \mathrm{CO}_{2}$. The study was approved by the Ethics Committee of Zhengzhou University, Zhengzhou, China.

Examination of morphological changes by a phase-contrast microscopic study. EC-109 cells $\left(2 \times 10^{5}\right.$ cells/well) were maintained in 12-well plates for $24 \mathrm{~h}$ and treated with various concentrations of baicalein $(0,10,20$ and $40 \mu \mathrm{M})$ for $24 \mathrm{~h}$. Morphological changes in cells due to each treatment procedure were observed and photographed under a phase-contrast microscope.

Cell viability assay. Proliferation of cells was determined by an MTT assay. Approximately 10,000 EC-109 cells/well were plated in 96-well plates. Following incubation overnight, cells were treated with baicalein $(0,10,20$ and $40 \mu \mathrm{M})$. At various time points $(24-72 \mathrm{~h})$ following baicalein treatment, the medium was removed and MTT ( $20 \mu \mathrm{l}$ of $5 \mathrm{mg} / \mathrm{ml}$ ) was added to each well and incubated at $37^{\circ} \mathrm{C}$ for $4 \mathrm{~h}$. The plates were spun and the purple precipitates of formazan were dissolved in $150 \mu \mathrm{l}$ DMSO. Absorbance was measured at $490 \mathrm{~nm}$ using an enzyme-linked immunosorbant asssay (ELISA) plate reader. The viability of baicalein-treated EC-109 cells was expressed as a percentage relative to non-baicalein-treated control cells. Control cells were considered to be $100 \%$ viable.

Plate colony forming assay. Suspensions of EC-109 cells were inoculated in 6-well flat-bottomed plates with a density of $3 \times 10^{2}$ cells/well and 3 wells/group. Cells were dispersed evenly by slightly shaking the plates and were then incubated with baicalein at different concentrations in RPMI-1640 medium, with $10 \% \mathrm{FBS}$ at $37^{\circ} \mathrm{C}$ and $5 \% \mathrm{CO}_{2}$ for 14 days, until the visible clones appeared. The medium was discarded and cells were carefully washed twice with PBS. Following fixation with methanol for $15 \mathrm{~min}$, cells were stained with Giemsa's solution for $15 \mathrm{~min}$ before washing with tap water and air-drying. Clones with $>50$ cells were counted with an ordinary optical microscope. All experiments were repeated in triplicate and the average values are presented.

Hoechst 33258 staining. Following treatment with baicalein at various concentrations for $48 \mathrm{~h}$, cells were washed twice with PBS and fixed in $1 \mathrm{ml}$ of $4 \%$ paraformaldehyde for $10 \mathrm{~min}$ at $4^{\circ} \mathrm{C}$. After washing twice with PBS, cells were stained with $100 \mu 1$ Hoechst 33258 in PBS for 15 min at room temperature in the dark, and then washed with PBS. Cells were mounted and examined by fluorescence microscopy (Olympus BX-51, Tokyo, Japan). Apoptotic cells were identified by the condensation and fragmentation of their nuclei.

DNA fragmentation assay. Following exposure to various concentrations of baicalein for $48 \mathrm{~h}, \mathrm{EC}-109$ cells were collected by centrifugation and washed twice with PBS. Cell pellets were resuspended in $40 \mu 1$ of lysis buffer (0.1 M EDTA; $0.1 \mathrm{M}$ Tris- $\mathrm{HCl}, \mathrm{pH} 8.0$ and $0.8 \%$ SDS) and subsequently treated with $10 \mu \mathrm{l}$ RNase $\mathrm{A}(50 \mu \mathrm{g} / \mathrm{ml})$ at $37^{\circ} \mathrm{C}$ for $1 \mathrm{~h}$, and with $10 \mu \mathrm{l}$ proteinase $\mathrm{K}(20 \mu \mathrm{g} / \mathrm{ml})$ at $50^{\circ} \mathrm{C}$ overnight. Extracted cellular DNA was subjected to agarose gel (2.0\%) chromatography at $35 \mathrm{~V}$ for $3 \mathrm{~h}$. Gels were photographed following staining with $0.5 \mu \mathrm{g} / \mathrm{ml}$ ethidium bromide.

Measurements of cells in early and late apoptosis. The ability of baicalein to induce apoptosis in EC-109 cells was examined by Annexin V-FITC/propidium iodide (PI) double-staining and flow cytometry. Preparations were treated with baicalein at various concentrations for $48 \mathrm{~h}$. Cells were then harvested, resuspended to $5 \times 10^{5} / \mathrm{ml}$ in binding buffer (10 mM HEPES, $\mathrm{pH} 7.4 ; 150 \mathrm{mM} \mathrm{NaCl} ; 5 \mathrm{mM} \mathrm{KCl} ; 1 \mathrm{mM} \mathrm{MgCl}_{2}$ and $1.8 \mathrm{mM}$ $\mathrm{CaCl}_{2}$ ), and doubly stained with Annexin V-FITC/PI according to the manufacturer's instructions. The percentages of viable, early apoptotic, late apoptotic and necrotic cells were determined using a FACSort flow cytometer (Becton Dickinson, San José, CA, USA).

Western blot analysis. EC-109 cells were treated with $20 \mu \mathrm{M}$ baicalein for 0-72 h. Then, cells were harvested and lysed on ice for $30 \mathrm{~min}$ in lysis buffer containing $50 \mathrm{mM}$ Tris-HCl, 
A

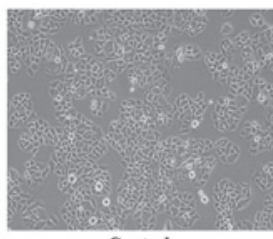

Control

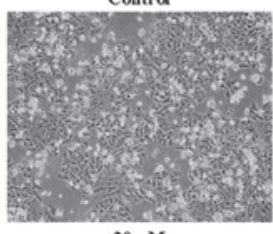

$20 \mu \mathrm{M}$
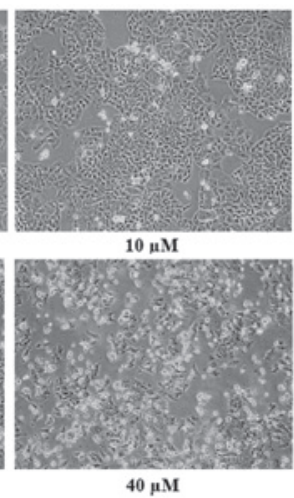

B

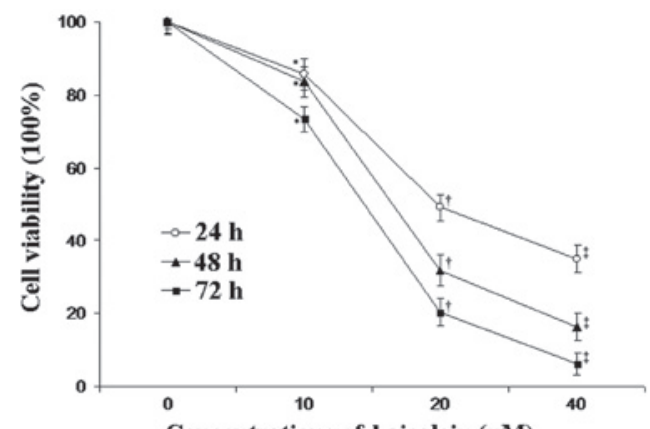

Concentrations of baicalein $(\mu \mathrm{M})$

Figure 1. Morphological changes and cell viability of EC-109 cells following treatment with baicalein. (A) Cells after treatment with $0,10,20$ and $40 \mu \mathrm{M}$ baicalein for $24 \mathrm{~h}$. (B) Concentration- and time-dependent effects of baicalein on EC-109 cell viability after cells were cultured with various concentrations of baicalein for 24, 48 and $72 \mathrm{~h}$ are demonstrated. Findings are presented as the mean \pm standard deviation for three independent experiments. ${ }^{*} \mathrm{P}<0.05$ compared with the solvent control; ${ }^{\dagger} \mathrm{P}<0.05$ compared with $10 \mu \mathrm{M}$ baicalein; ${ }^{\ddagger} \mathrm{P}<0.05$ compared with $20 \mu \mathrm{M}$ baicalein.

A
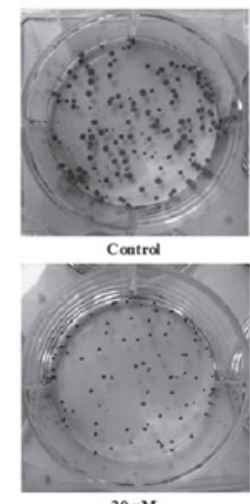

$20 \mu \mathrm{MI}$

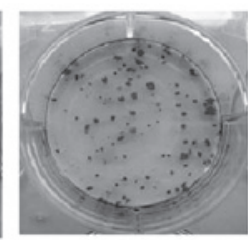

$10 \mu \mathrm{M}$

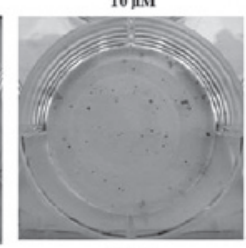

$40 \mathrm{\mu N}$

B

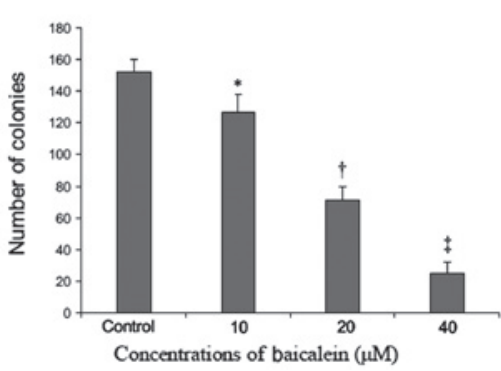

Figure 2. Inhibition of colony formation by baicalein. (A) Colony formation of EC-109 cells following treatment with baicalein at varying concentrations. (B) The number of colonies. Findings are presented as mean \pm standard deviation for three independent experiments. " $\mathrm{P}<0.01$ compared with the solvent control; ${ }^{\dagger} \mathrm{P}<0.01$ compared with $10 \mu \mathrm{M}$ baicalein; ${ }^{\dagger} \mathrm{P}<0.01$ compared with $20 \mu \mathrm{M}$ baicalein.
pH 8.0; $150 \mathrm{mM} \mathrm{NaCl} ; 20 \mathrm{mM}$ EDTA; $50 \mathrm{mM} \mathrm{NaF} ; 1 \%$ NP-40 and $0.02 \% \mathrm{NaN}_{3}$. The lysis buffer also contained protease inhibitors ( $1 \mathrm{mM}$ PMSF and $1 \mu \mathrm{g} / \mathrm{ml}$ aprotinin) to prevent proteolysis and/or dephosphorylation. Lysates were collected following centrifugation at 12,000 rpm for $20 \mathrm{~min}$ at $4^{\circ} \mathrm{C}$. Protein levels were quantified using the Lowry method (28). Equivalent weights of protein (50 $\mu \mathrm{g} / \mathrm{lane})$ were separated by $15 \%$ sodium dodecyl sulfate polyacrylamide gel electrophoresis (SDS-PAGE) and transferred to polyvinylidine fluoride (PVDF) membranes. Membranes were blocked with $5 \%$ non-fat milk in TBST buffer for $1 \mathrm{~h}$ and then incubated with primary antibodies at 1:1000 dilution in 5\% non-fat milk overnight at $4^{\circ} \mathrm{C}$. Membranes were then washed twice and incubated with secondary antibodies conjugated with horseradish peroxidase at 1:1,000 dilution for $1 \mathrm{~h}$ at room temperature. After extensive washing with TBST, protein bands were visualized by the enhanced chemiluminescence reagent (Amersham Pharmacia Biotech, Tokyo, Japan). The relative expression ratios of experimentals and controls were calculated according to the reference band of $\beta$-actin by the density using the software Un-SCAN-IT gel Version 6.1 (Silk Scientific, Inc., Orem, UT, USA). Experiments were repeated in triplicate.

Statistical analysis. Data are expressed as the mean \pm standard deviation. Significance of the difference in means between groups was obtained by analysis of variance (ANOVA). $\mathrm{P}<0.05$ was considered to indicate a statistically significant difference.

\section{Results}

Inhibition of cell growth by baicalein. Cell morphology was examined using phase-contrast microscopy. Microscopic observations revealed that EC-109 cells exposed to various concentrations of baicalein underwent significant morphological alterations (Fig. 1A). When exposed to baicalein at a concentration of $10 \mu \mathrm{M}$, EC-109 cells began to shrink and retract from the neighboring cells. At a concentration of $20 \mu \mathrm{M}$, floating cells began to appear in the culture medium. EC-109 cells incubated in concentrations of $40 \mu \mathrm{M}$ of baicalein lost their original morphological (flat, polygonal) shape and additional floating cells appeared. An MTT assay was implemented to examine the viability of EC-109 cells exposed to $0,10,20$ and $40 \mu \mathrm{M}$ of baicalein in the culture medium for 24,48 and $72 \mathrm{~h}$. It was found that baicalein significantly decreased the cell viability of EC-109 cells in a concentrationand time-dependent manner (Fig. 1B).

Inhibition of colony formation. Baicalein also suppressed plate colony formation of EC-109 cells at 14 days post-seeding (Fig. 2A). The number of colonies for control preparations was $152 \pm 5.1$. By contrast, the number of colonies that formed for preparations treated with baicalein at 10,20 and $40 \mu \mathrm{M}$ were $127 \pm 4.5,71 \pm 9.2$ and $25 \pm 4.5$, respectively $(\mathrm{P}<0.05)$ (Fig. $2 \mathrm{~B}$ ).

Baicalein induces apoptosis in EC-109 cells. Hoechst 33258 stain is sensitive to DNA and is used to assess changes in nuclear morphology. The Hoechst 33258 staining assay revealed that cells demonstrated apoptotic features including nuclear shrinkage and chromatin condensation or fragmenta- 
A
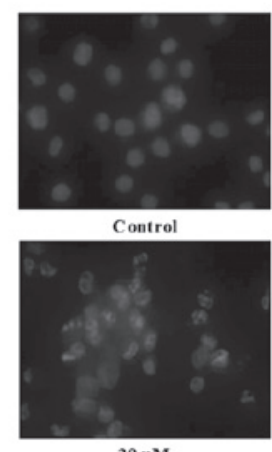

$20 \mu \mathrm{M}$

C

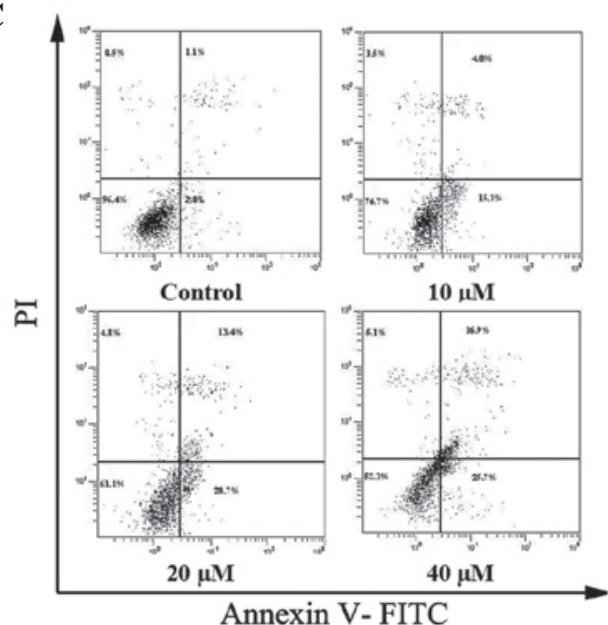

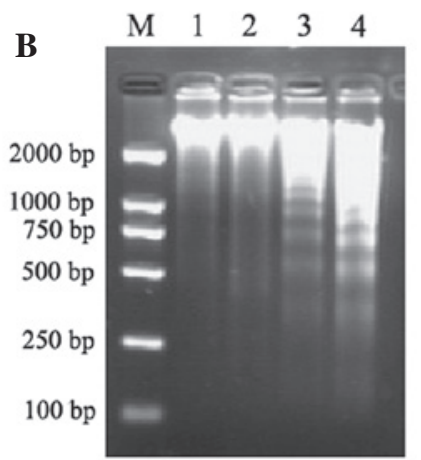

D

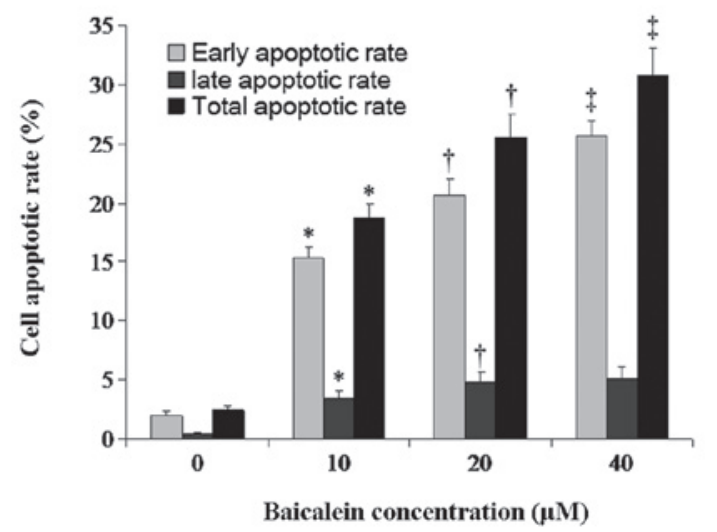

Figure 3. Induction of apoptosis in EC-109 cells by baicalein. (A) Hoechst 33258 staining. The impact of cell apoptosis of baicalein on cultured EC-109 cells without baicalein or following treatment with baicalein at 10, 20 and $40 \mu \mathrm{M}$ for $48 \mathrm{~h}$. (B) EC-109 cells were treated for $48 \mathrm{~h}$ with baicalein at 0 (lane 1 ), 10 (lane 2), 20 (lane 3), and $40 \mu \mathrm{M}$ (lane 4). Lane M shows the migration of D2000 markers (100, 250, 500, 750, 1,000 and 2,000 bp). (C) Annexin V-FITC/PI double staining and flow cytometry were used to determine the percentages of cells in apoptosis. Viable, early apoptotic, late apoptotic and necrotic cells were determined following treatment for $48 \mathrm{~h}$ with baicalein at various concentrations. Bottom left quadrants, viable cells; bottom right quadrants, early apoptotic cells; top right quadrants, late apoptotic cells; top left quadrants, necrotic cells. (D) Percentages of cells in apoptosis at each baicalein concentration. Cells in the bottom and top right quadrants were summed to obtain the total number of apoptotic cells. Findings are presented as the mean of three similar experiments \pm standard deviation. ${ }^{*} \mathrm{P}<0.05$ compared with the solvent control; ${ }^{\dagger} \mathrm{P}<0.05$ compared with $10 \mu \mathrm{M}$ baicalein; ${ }^{\star} \mathrm{P}<0.05$ compared with $20 \mu \mathrm{M}$ baicalein.

tion, following treatment with baicalein for $48 \mathrm{~h}$. The rate of cells with a profile of chromatin condensation and fragmented fluorescent nuclei increased in a concentration-dependent manner (Fig. 3A). The ability of baicalein to induce DNA fragmentation, a hallmark of apoptosis, was examined after $48 \mathrm{~h}$ of culture. No significant fragmentation was observed in preparations treated with either solvent or $10 \mu \mathrm{M}$ baicalein. However, fragmentation was clearly observable in preparations treated with 20 and $40 \mu \mathrm{M}$ baicalein (Fig. 3B). An annexin V-FITC and PI double-staining technique was implemented to investigate whether baicalein induced apoptosis in these cells. The percentage of EC-109 cells undergoing early apoptotic cell death was increased by baicalein in a concentration-dependent manner (Fig. 3C). The percentage of cells undergoing apoptosis was determined by the sum of cells in early and late apoptosis. After $48 \mathrm{~h}$ of treatment, $2.5 \pm 0.35$, $18.8 \pm 1.15,25.5 \pm 1.99$ and $30.8 \pm 2.25 \%$ of cells were apoptotic at concentrations of $0,10,20$ and $40 \mu \mathrm{M}$ of baicalein, respectively (Fig. 3D).

Activation of the intrinsic mitochondrial apoptotic pathway. It was considered essential to ascertain whether baicalein suppressed the viability of EC-109 cells and promoted DNA fragmentation in such cells through activation of the intrinsic (mitochondrial) apoptotic pathway. Therefore, expression of the relevant apoptosis-related proteins was examined by western blot analysis. Treatment with baicalein increased the expression of pro-apoptotic proteins including Bax, activated (cleaved) caspase-3 and -9, and activated (cleaved) PARP. By contrast, expression of the anti-apoptotic protein Bcl-2, procaspase-3 and -9 , and of the inactive form of PARP, was decreased following treatment with the drug. The relative expression ratios of these proteins following baicalein treatment was quantified by the density, and findings are presented in Fig. 4.

Suppression of the PI3K/Akt pathway. The effects of baicalein on suppression of the Akt pathway in EC-109 cells were examined. Expression of the following components in their various forms were measured: i) Akt (inactive) and p-Akt (the activated form of $\mathrm{Akt}$ ); ii) the transcription factor $\mathrm{NF}-\kappa \mathrm{B}$, the $\mathrm{NF}-\kappa \mathrm{B}$ inhibitor, $\mathrm{I} \kappa \mathrm{B}$, and the degradable form of $\mathrm{I} \kappa \mathrm{B}, \mathrm{p}-\mathrm{I} \kappa \mathrm{B}$; iii) the cell cycle regulatory kinase $\mathrm{mTOR}$ (inactive) and p-mTOR, the phosphorylated and active form of the kinase. 


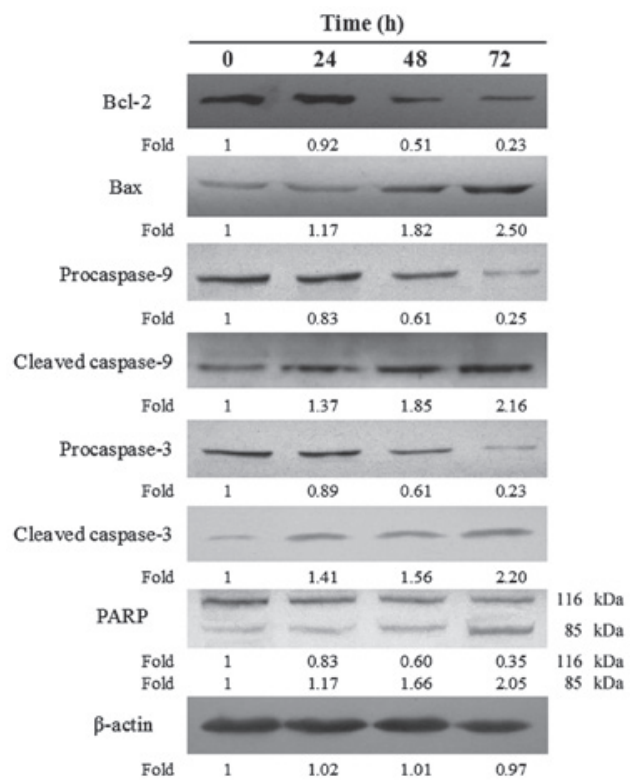

Figure 4. Apoptosis induction via intrinsic apoptotic pathways over time. EC-109 cells were treated with $20 \mu \mathrm{M}$ baicalein for the times indicated Expression of $\beta$-actin, Bcl-2, Bax, procaspase- 9 , cleaved caspase-9, procaspase-3, cleaved caspase-3, uncleaved (116 kDa) and cleaved (85 kDa) PARP was analyzed by western blot analysis and the relative ratio was calculated by the density.

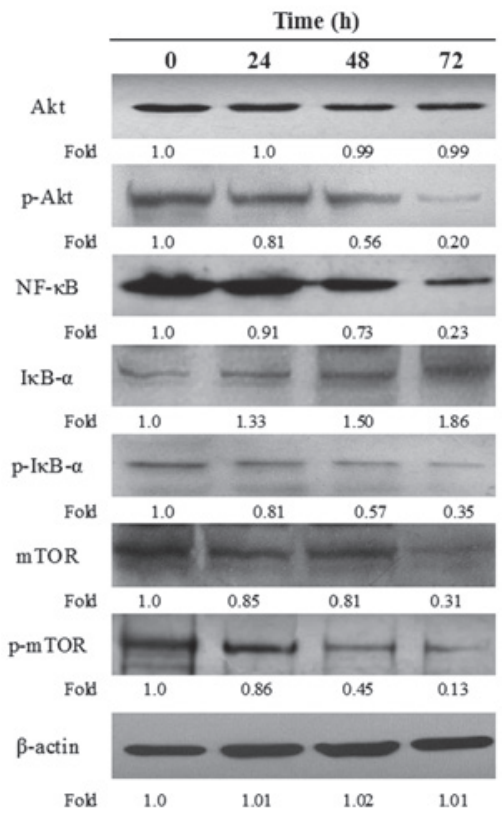

Figure 5. Expression of proteins associated with the PI3K/Akt signaling following various treatment times of EC-109 cells with $20 \mu \mathrm{M}$ baicalein. Expression of $\beta$-actin, Akt, p-Akt, NF- $\kappa \mathrm{B}, \mathrm{I} \kappa \mathrm{B}, \mathrm{p}-\mathrm{I} \kappa \mathrm{B}, \mathrm{mTOR}$ and p-mTOR was analyzed by western blot analysis and the relative ratio was calculated by the density.

A decrease in p-Akt and p-mTOR was observed at $24 \mathrm{~h}$ of baicalein treatment. Dramatic reductions in the expression of $\mathrm{NF}-\kappa \mathrm{B}$ and $\mathrm{p}-\mathrm{I} \kappa \mathrm{B}$ were observed in response to baicalein at $48 \mathrm{~h}$ of baicalein treatment. These reductions were timedependent. By contrast, expression of $I \kappa B$ increased with the time of baicalein treatment. The marked decreases in expression of total cellular NF- $\mathrm{NB}$ and $\mathrm{p}-\mathrm{I} \kappa \mathrm{B}$, accompanied by significant increases in $\mathrm{I} \kappa \mathrm{B}$ expression, in response to baicalein treatment, were interpreted to indicate a condition wherein nuclear NF-кB signaling was dramatically impaired (Fig. 5).

\section{Discussion}

The current study has demonstrated that baicalein is toxic to esophageal carcinoma cells in culture. Treatment with this flavone resulted in a marked decrease in the viability of cultured EC-109 cells and in the number of colonies that these cells formed. Baicalein treatment caused EC-109 cells to undergo apoptosis, as demonstrated by changes in nuclear morphology, an increase in the percentage of Annexin V-stainable cells and an increase in DNA fragmentation.

The PI3K/Akt growth signaling pathway comprises a series of serine/threonine kinase cascades that regulate a variety of cellular processes including cell cycle progression, cell survival and migration, and protein synthesis. Activated Akt acts to phosphorylate Bad, Bax and caspase-9 or activate the $\mathrm{NF}-\kappa \mathrm{B}$ pathway to promote the resistance of cancer cells to apoptosis (29-32). In the present study, inhibition of Akt phosphorylation, as opposed to downregulation of Akt expression, was observed during treatment of EC-109 cells with baicalein. As Akt acts early on in the PI3K/Akt signaling pathway, it is conceivable that the growth-suppressive effects of baicalein in EC-109 cells are attributable to an interaction of the drug with the kinase. Due to the fact that PI3K expression/activity was not measured in the present study, the involvement of this kinase in the observed effects of baicalein remains unclear. Future studies with various esophageal carcinoma cells lines have been planned to explore the possibility that PI3K is targeted by baicalein.

$N F-\kappa \mathrm{B}$ is a critical transcription factor in a variety of physiological and pathological processes. One particular function of $N F-\kappa B$ is to promote cell survival through the induction of target genes, whose products inhibit components of the apoptotic machinery in normal and cancerous cells (33). It has been demonstrated that NF- $\kappa$ B plays a key role in progression, apoptosis and lymph node metastasis in ESCC (34-36). As a downstream component of the PI3K/ Akt pathway (37), NF- $\mathrm{B}$ primarily resides in the cytosol in an inactive form; a heterodimer composed of p50 and p65 through an interaction with the inhibitory protein IкB (38). Agonist-induced stimulation resulted in phosphorylation and subsequent proteosomal degradation of $\mathrm{I} \kappa \mathrm{B}$, thereby inducing nuclear translocation of $\mathrm{NF}-\kappa \mathrm{B}$ to promote the transcription of its target genes (38). Activated Akt indirectly signals $\mathrm{I} \kappa \mathrm{B}$ phosphorylation, thereby promoting transcription of anti-apoptotic genes, whereas inactivation of Akt promotes apoptosis. The present study demonstrated that treatment of EC-109 cells with baicalein induced apoptosis by suppressing components of the PI $3 \mathrm{~K} / \mathrm{Akt} / \mathrm{NF}-\kappa \mathrm{B}$ signaling pathway; the expression of $\mathrm{p}-\mathrm{Akt}, \mathrm{NF}-\kappa \mathrm{B}$, and $\mathrm{p}-\mathrm{I} \kappa \mathrm{B}$. These decreases were observed concurrently with increased expression of non-phosphorylated IкB.

mTOR, a major downstream target of the PI3K/Akt pathway, is an essential regulator of cell proliferation, protein synthesis and the modulation of signals in various signaling 
pathways $(39,40)$. The mTOR pathway has a central role in cell growth, as well as in invasion and metastasis of tumors (41-43). It has been demonstrated that the mTOR/p70S6K pathway was activated in ESCC, and rapamycin or siRNA against mTOR rapidly inhibited expression of $\mathrm{mTOR}$, arrested cells in the G0/G1 phase and induced apoptosis of ESCC cells (44). In the present study, the results revealed that a decrease in the expression of mTOR and p-mTOR along with downregulated expression of p-Akt upon baicalein treatement, corroborated well with the growth inhibition and induction of apoptosis in EC-109 cells.

Suppression of Akt in cancer cells is associated with activation of the mitochondrial apoptotic pathway involving the caspase-9-dependent caspase cascade (45). Caspase-3, a downstream caspase, is activated by caspase-9. Caspase-3 activation leads to cleavage and inactivation of key cellular proteins such as PARP and the DNA fragmentation factor (46). In our study, treatment of EC-109 cells with baicalein was revealed to increase the level of cleaved caspase- 9 concurrently with a decrease in procaspase- 9 protein, to increase level of cleaved caspase- 3 concurrently with a decrease in procaspase- 3 protein, to increase expression of cleaved PARP concurrently with decreased expression of uncleaved PARP, and to promote DNA degradation. These findings support the hypothesis that apoptotic death in baicalein-treated EC-109 cells is mediated by the following events in sequence: Cleavage of procaspase-9, cleavage of procaspase-3, cleavage of PARP and ultimately degradation of DNA. To further delineate the signaling events involved in baicalein induced apoptosis, the potential role of baicalein in regulating Bax and Bcl-2 proteins, which regulate the essential change in mitochondrial membrane permeability for apoptosis, was examined (47). As a result, baicalein markedly decreased anti-apoptotic Bcl-2 protein levels, while the levels of proapoptotic Bax protein concomitantly increased. From these data, it may be concluded that baicalein induced EC-109 cell apoptosis by activating the intrinsic mitochondrial pathway.

In summary, the results of the present study indicate that baicalein induced apoptosis in human ESCC EC-109 cells. This is mediated through suppression of the PI3K/Akt/NF- $\mathrm{B}$ and PI3K/Akt/mTOR signaling pathways which involves activation of the mitochondrial death pathway components (including Bcl-2 family proteins), as well as activation of caspase- 3 and PARP. The results of the present study suggest that baicalein may be an effective chemopreventive agent for ESCC. However, further studies are required to determine the upstream signaling that is involved in the inhibition of this signaling pathway by baicalein in ESCC cells. Furthermore, to delineate the potential of this agent in esophageal cancer treatment, we intend to examine the antitumor effects of baicalein in an animal model.

\section{Acknowledgements}

This study was supported by a research grant from Zhengzhou University for Talent Recruitment. The authors would like to thank Dr Hongli Zhang (Institute of Hematology and Blood Diseases, Chinese Academy of Medical Sciences and Peking Union Medical College, China) for his English correction and useful discussion regarding this work.

\section{References}

1. Kamangar F, Dores GM and Anderson WF: Patterns of cancer incidence, mortality, and prevalence across five continents: defining priorities to reduce cancer disparities in different geographic regions of the world. J Clin Oncol 24: 2137-2150, 2006.

2. Parkin DM, Bray FI and Devesa SS: Cancer burden in the year 2000. The global picture. Eur J Cancer 37: S4-66, 2001.

3. Sant M, Allemani C, Santaquilani M, Knijn A, Marchesi F, and Capocaccia R; EUROCARE Working Group: EUROCARE-4. Survival of cancer patients diagnosed in 1995-1999. Results and commentary. Eur J Cancer 45: 931-991, 2009.

4. Xing D, Tan W and Lin D: Genetic polymorphisms and susceptibility to esophageal cancer among Chinese population (review). Oncol Rep 10: 1615-1623, 2003.

5. Stoner GD and Gupta A: Etiology and chemoprevention of esophageal squamous cell carcinoma. Carcinogenesis 22: 1737-1746, 2001.

6. Besharat S, Jabbari A, Semnani S, Keshtkar A and Marjani J: Inoperable esophageal cancer and outcome of palliative care. World J Gastroenterol 14: 3725-3728, 2008.

7. Alibakhshi A, Aminian A, Mirsharifi R, Jahangiri Y, Dashti H and Karimian F: The effect of age on the outcome of esophageal cancer surgery. Ann Thorac Med 4: 71-74, 2009.

8. Wei WT, Chen H, Ni ZL, Liu HB, Tong HF, Fan L, Liu A, Qiu MX, Liu DL, Guo HC, Wang ZH and Lin SZ: Antitumor and apoptosispromoting properties of emodin, an anthraquinone derivative from Rheum officinale Baill, against pancreatic cancer in mice via inhibition of Akt activation. Int J Oncol 39: 1381-1390, 2011.

9. Ma YS, Weng SW, Lin MW, Lu CC, Chiang JH, Yang JS, Lai KC, Lin JP, Tang NY, Lin JG and Chung JG: Antitumor effects of emodin on LS1034 human colon cancer cells in vitro and in vivo: roles of apoptotic cell death and LS1034 tumor xenografts model. Food Chem Toxicol 50: 1271-1278, 2012.

10. Kimura Y, Kubo M, Tani T, Arichi S, Ohminami H and Okuda H: Studies on Scutellariae radix. III. Effects on lipid metabolism in serum, liver and fat cells of rats. Chem Pharm Bull 29: 2308-2312, 1981.

11. Lin CC and Shieh DE: The anti-inflammatory activity of Scutellaria rivularis extracts and its active components, baicalin, baicalein and wogonin. Am J Chin Med 24: 31-36, 1996.

12. $\mathrm{Lu} \mathrm{Y}$, Joerger R and Wu C: Study of the chemical composition and antimicrobial activities of ethanolic extracts from roots of Scutellaria baicalensis Georgi. J Agric Food Chem 59: 10934-10942, 2011.

13. Miocinovic R, McCabe NP, Keck RW, Jankun J, Hampton JA and Selman SH: In vivo and in vitro effect of baicalein on human prostate cancer cells. Int J Oncol 26: 241-246, 2005.

14. Ma Z, Otsuyama K, Liu S, Abroun S, Ishikawa H, Tsuyama N, Obata M, Li FJ, Zheng X, Maki Y, Miyamoto K and Kawano MM: Baicalein, a component of Scutellariae radix from Huang-LianJie-Du-Tang (HLJDT), leads to suppression of proliferation and induction of apoptosis in human myeloma cells. Blood 105: 3312-3318, 2005.

15. Chen CH, Huang LL, Huang CC, Lin CC, Lee Y and Lu FJ: Baicalein, a novel apoptotic agent for hepatoma cell lines: a potential medicine for hepatoma. Nutr Cancer 38: 287-295, 2000.

16. Lee HZ, Leung HW, Lai MY and Wu CH: Baicalein induced cell cycle arrest and apoptosis in human lung squamous carcinoma CH27 cells. Anticancer Res 25: 959-964, 2005.

17. Chao JI, Su WC and Liu HF: Baicalein induces cancer cell death and proliferation retardation by the inhibition of CDC 2 kinase and survivin associated with opposite role of p38 mitogen-activated protein kinase and AKT. Mol Cancer Ther 6: 3039-3048, 2007.

18. Shieh DE, Cheng HY, Yen MH, Chiang LC and Lin CC: Baicalin-induced apoptosis is mediated by Bcl-2-dependent, but not p53-dependent, pathway in human leukemia cell lines. Am J Chin Med 34: 245-261, 2006.

19. Lu HF, Hsueh SC, Ho YT, Kao MC, Yang JS, Chiu TH, Huamg SY, Lin CC and Chung JG: ROS mediates baicalininduced apoptosis in human promyelocytic leukemia HL-60 cells through the expression of the Gadd153 and mitochondrialdependent pathway. Anticancer Res 27: 117-125, 2007.

20. Kuo HM, Tsai HC, Lin YL, Yang JS, Huang AC, Yang MD, Hsu SC, Chung MC, Gibson Wood W and Chung JG: Mitochondrial-dependent caspase activation pathway is involved in baicalein-induced apoptosis in human hepatoma J5 cells. Int J Oncol 35: 717-724, 2009. 
21. Altomare DA and Testa JR: Perturbations of the AKT signaling pathway in human cancer. Oncogene 24: 7455-7464, 2005.

22. Tokunaga E, Oki E, Egashira A, Sadanaga N, Morita M, Kakeji Y and Maehara Y: Deregulation of the Akt pathway in human cancer. Curr Cancer Drug Targets 8: 27-36, 2008.

23. Li H, Gao Q, Guo L and Lu SH: The PTEN/PI3K/Akt pathway regulates stem-like cells in primary esophageal carcinoma cells. Cancer Biol Ther 11: 950-958, 2011.

24. Li B, Cheung PY, Wang X, Tsao SW, Ling MT, Wong YC and Cheung AL: Id-1 activation of PI3K/Akt/NFkappaB signaling pathway and its significance in promoting survival of esophageal cancer cells. Carcinogenesis 28: 2313-2320, 2007.

25. Li B, Tsao SW, Li YY, Wang X, Ling MT, Wong YC, He QY and Cheung AL: Id-1 promotes tumorigenicity and metastasis of human esophageal cancer cells through activation of PI3K/AKT signaling pathway. Int J Cancer 125: 2576-2585, 2009.

26. Zhao H, Yang J, Fan T, Li S and Ren X: RhoE functions as a tumor suppressor in esophageal squamous cell carcinoma and modulates the PTEN/PI3K/Akt signaling pathway. Tumour Biol 33: 1363-1374, 2012.

27. Agarwal S, Achari C, Praveen D, Roy KR, Reddy GV and Reddanna P: Inhibition of 12 -LOX and COX-2 reduces the proliferation of human epidermoid carcinoma cells (A431) by modulating the ERK and PI3K-Akt signalling pathways. Exp Dermatol 18: 939-946, 2009.

28. Lowry OH, Rosebrough NJ, Farr AL, and Randall RJ: Protein measurement with the Folin phenol reagent. J Biol Chem 193: $265-275,1951$

29. Song L, Xiong H, Li J, Liao W, Wang L, Wu J and Li M: Sphingosine kinase-1 enhances resistance to apoptosis through activation of $\mathrm{PI} 3 \mathrm{~K} / \mathrm{Akt} / \mathrm{NF}-\kappa \mathrm{B}$ pathway in human non-small cell lung cancer. Clin Cancer Res 17: 1839-1849, 2011.

30. Tsuruta F, Masuyama N and Gotoh Y: The phosphatidylinositol 3-kinase (PI3K)-Akt pathway suppresses Bax translocation to mitochondria. J Biol Chem 277: 14040-14047, 2002.

31. Datta SR, Dudek H, Tao X, Masters S, Fu H, Gotoh Y and Greenberg ME: Akt phosphorylation of BAD couples survival signals to the cell-intrinsic death machinery. Cell 91: 231-241, 1997.

32. Cardone MH, Roy N, Stennicke HR, Salvesen GS, Franke TF, Stanbridge E, Frisch S and Reed JC: Regulation of cell death protease caspase-9 by phosphorylation. Science 282: 1318-1321, 1998.

33. Shen HM and Tergaonkar V: NFKB signaling in carcinogenesis and as a potential molecular target for cancer therapy. Apoptosis 14: 348-363, 2009.

34. Tian F, Fan T, Jiang Y, Zhang X and Wang X: A small interfering RNA targeting NF- $\kappa$ B p65 alone or combined with 5-FU inhibits growth of esophageal squamous cell carcinoma in nude mice. Pathol Res Pract 208: 32-38, 2012.
35. Tian F, Zang WD, Hou WH, Liu HT and Xue LX: Nuclear factor-kB signaling pathway constitutively activated in esophageal squamous cell carcinoma cell lines and inhibition of growth of cells by small interfering RNA. Acta Biochim Biophys Sin 38: 318-326, 2006.

36. Su C, Chen Z, Luo H, Su Y, Liu W, Cai L, Wang T, Lei Y and Zhong B: Different patterns of NF- $\kappa \mathrm{B}$ and Notch1 signaling contribute to tumor-induced lymphangiogenesis of esophageal squamous cell carcinoma. J Exp Clin Cancer Res 30: 85, 2011.

37. Madrid LV, Mayo MW, Reuther JY and Baldwin AS Jr: Akt stimulates the transactivation potential of the RelA/p65 Subunit of NF-kappa B through utilization of the Ikappa B kinase and activation of the mitogen-activated protein kinase p38. J Biol Chem 276: 18934-18940, 2001.

38. Vermeulen L, Vanden Berghe W and Haegeman G: Regulation of NF- $\kappa \mathrm{B}$ transcriptional activity. Cancer Treat Res 130: 89-102, 2006.

39. Fingar DC, Richardson CJ, Tee AR, Cheatham L, Tsou C and Blenis J: mTOR controls cell cycle progression through its cell growth effectors S6K1 and 4E-BP1/eukaryotic translation initiation factor 4E. Mol Cell Biol 24: 200-216, 2004.

40. Fingar DC, Salama S, Tsou C, Harlow E and Blenis J: Mammalian cell size is controlled by mTOR and its downstream targets S6K1 and 4EBP1/eIF4E. Genes Dev 16: 1472-1487, 2002.

41. Bjornsti MA and Houghton PJ: The TOR pathway: a target for cancer therapy. Nat Rev Cancer 4: 335-348, 2004.

42. Xu G, Zhang W, Bertram P, Zheng XF and McLeod H Pharmacogenomic profiling of the PI3K/PTEN-AKT-mTOR pathway in common human tumors. Int J Oncol 24: 893-900, 2004.

43. Sun SY, Rosenberg LM, Wang X, Zhou Z, Yue P, Fu H and Khuri FR: Activation of Akt and eIF4E survival pathways by rapamycin-mediated mammalian target of rapamycin inhibition. Cancer Res 65: 7052-7058, 2005

44. Hou G, Xue L, Lu Z, Fan T, Tian F and Xue Y: An activated $\mathrm{mTOR} / \mathrm{p} 70 \mathrm{~S} 6 \mathrm{~K}$ signaling pathway in esophageal squamous cell carcinoma cell lines and inhibition of the pathway by rapamycin and siRNA against mTOR. Cancer Lett 253: 236-248, 2007.

45. Chang F, Lee JT, Navolanic PM, Steelman LS, Shelton JG, Blalock WL, Franklin RA and McCubrey JA: Involvement of PI3K/Akt pathway in cell cycle progression, apoptosis, and neoplastic transformation: a target for cancer chemotherapy. Leukemia 17: 590-603, 2003.

46. Hengartner MO: The biochemistry of apoptosis. Nature 407: 770-776, 2000

47. Orrenius S: Mitochondrial regulation of apoptotic cell death. Toxicol Lett 149: 19-23, 2004. 